\title{
Problems and Solutions of Construction Project Cost Management
}

\author{
Wang Miaoting, Luo Ni \\ Shaanxi Technical College of Finance \& Economics, Xianyang, China, 712000
}

Keywords: construction engineering; cost management; problem; solution

Abstract: While the construction industry is developing rapidly, the competition among construction enterprises is becoming increasingly fierce. In order to effectively enhance the competitiveness of enterprises and improve the economic benefits of enterprises, construction enterprises need to strengthen the construction project cost management. This paper analyzes the problems existing in the cost management of construction projects and proposes measures to strengthen the construction cost management of construction projects.

\section{Introduction}

As China's urbanization process continues to accelerate, the development speed of construction enterprises continues to increase, and competition among construction enterprises is becoming increasingly fierce. How architecture companies stand out in this fierce competition is a problem that many construction companies need to study in depth. The study found that in order to improve the economic efficiency of construction enterprises and promote the stability and sustainable development of enterprises, it is necessary to minimize the cost of enterprises and improve the technical level of enterprises. Cost control is closely related to the construction project cost management work. Therefore, construction companies need to take targeted measures according to the problems existing in the cost management work, so as to achieve your goal of reducing construction costs and improving cost management.

\section{Problems in construction project cost management}

\subsection{Process control work is not perfect}

In the process of construction engineering construction, multiple links will be involved, and each link will take a certain period of time. Each construction link needs the support of corresponding funds. Therefore, in order to improve the construction project cost management effect, it is necessary to adopt the whole process cost management. the way. The study found that some construction companies in China have problems in the management control of construction projects. In short, during the construction of the project, the construction company did not manage and control the entire process, which caused the construction company to fail to find the shortcomings in the construction. At the same time, during the construction process of the project, the construction company did not establish a sound responsibility system, nor did it implement the 
responsibility system. As a result, the construction company did not reasonably assign the duties of each staff member, resulting in some construction workers having weak sense of responsibility during the construction process. The problems of slow progress and insufficient work quality will increase the construction cost and affect the project cost management effect. In addition, some construction companies have not strengthened the management and control of construction equipment. Construction project construction will inevitably require the use of a large amount of construction equipment. The cost of leasing, purchase, maintenance, etc. will be included in the cost of the construction project. If the construction enterprise does not strengthen the management and maintenance of the construction equipment, it will increase its maintenance and maintenance costs, and thus increase the cost of construction projects affects the economic benefits of enterprises.

\subsection{Construction cost management system is relatively backward}

In order to ensure that relevant policies can be fully implemented, construction enterprises need to improve relevant systems. However, China's construction enterprise engineering cost management system is relatively backward, which is also an important factor affecting the development speed and stability of construction enterprises. First of all, construction companies pay less attention to the project cost management system, and their construction is relatively backward. Some construction enterprise managers in China pay insufficient attention to the project cost management work, and the project cost management system formulated by them is not advanced enough, which can no longer meet the needs of social development. In addition, in the current development of China's economy and science and technology, the project cost management system needs to be continuously improved according to the level of economic development, construction technology and related policies, so as to improve the efficiency of project cost management and improve the economic efficiency of enterprises; secondly, the backward of the project cost management system will affect the development speed of construction enterprises. The backwardness of the project cost management system not only shows that the project cost management system is relatively backward at the level of the construction industry, but also the project cost management system formulated within the construction enterprise is not advanced enough. In recent years, the market price of building materials has been rising steadily. Some construction companies have adopted illegal bidding and contracting methods for economic benefits. Some of the management systems formulated by some construction enterprises have not been fully implemented, which will directly affect the construction project construction costs and the stability of construction enterprises.

\section{Measures to strengthen construction project cost management}

In order to effectively improve the construction project cost management level and improve the economic efficiency of the enterprise, the construction enterprise needs to take targeted measures to improve the construction project cost management level in view of the problems existing in the construction project cost management work, which is of great significance for improving the economic benefits of construction enterprises.

\subsection{Full implementation of the whole process cost management concept}

\subsubsection{Decision-making cost control}

The main content of cost management and control in the decision-making process of construction engineering is to conduct project feasibility study and ensure the balance between 
investment and income. In the feasibility study process, it is also necessary to analyze the construction cost, operation and maintenance costs, so as to ensure the accuracy of the feasibility study report and ensure the economic benefits of the construction enterprise.

During the feasibility analysis process, some construction enterprises did not conduct comprehensive and scientific analysis of the project. For example, the external environment such as the geological environment, land acquisition, water and electricity supply, and traffic conditions of the construction project was not thoroughly studied and analyzed. The evaluation report thus formed does not fully demonstrate the construction cost of the construction project, resulting in an increase in construction engineering costs.

\subsubsection{Design link cost control}

The quality of construction engineering design will also have a certain impact on the cost of construction engineering. Therefore, in order to strengthen the construction cost management, it is necessary to strengthen the construction cost management work from the design link, which can be started from the following aspects:

First, when selecting a construction engineering design enterprise, it is necessary to know its qualifications in detail to ensure that the professional quality and professional ability of the designer can meet the requirements, so as to ensure the rationality of the construction engineering design plan; secondly, the quota design method is required. According to the feasibility study report or the construction project implementation plan, the construction project scale, construction content and total investment amount shall be clearly defined, and the construction drawing design and estimated total construction amount shall be carried out according to the design. In addition, in the design process, it is necessary to design according to the investment limit on the basis of ensuring the complete function of each professional, reduce the probability of unreasonable change, and control the total investment amount. In short, it is to reduce the construction project construction cost and improve Enterprise economic benefits. When using the quota design method, the investment and engineering quantity should be decomposed, so that the management project can limit the investment limit of the construction project while ensuring that the design meets the design standards and design specifications. Third, to ensure the design of the limit. The requirements can be fully implemented, and a system of rewards and punishments needs to be established. Departments and individuals who have conscientiously implemented the design requirements for quotas and have a good working attitude should be given spiritual and material rewards. Conversely, departments and individuals who have not designed according to the design requirements of the quotas should be criticized and punished. Only by formulating and implementing the reward and punishment system can we inspire the enthusiasm of all departments and personnel to ensure the scientific design of the architectural design.

\subsubsection{Cost control of bidding and bidding}

First, in order to ensure that the bidding work can proceed smoothly, it is necessary to clarify the bidding target. In the selection process, it is necessary to select the construction project that is consistent with the technical level and construction capacity of the enterprise. Therefore, on the basis of satisfying the bidding requirements of the enterprise, the probability of winning the enterprise can be improved, which is very important for promoting the development of the enterprise. Second, the enterprise needs to be detailed answer corporate bidding questions. Before the bidding of the construction enterprise, it is necessary to analyze the bidding documents in detail, and negotiate with the bidding enterprises for the questions, so as to avoid conflicts in the future; third, in the construction project bidding and bidding, the construction management department 
needs to submit the bidding documents. Recording and scientifically formulating the construction organization design plan according to the bidding Wen Huan, the construction site exploration results, and the area where the construction project is located. In addition, the construction equipment management, procurement and other departments need to analyze and find the chart documents in detail, and analyze the cost of each construction link of the construction project in detail according to the construction technology level, engineering construction requirements, cost control requirements and other factors. If unreasonable conditions are found when reading the bidding documents, it is necessary to negotiate with the bidding party in time, which has an important impact on the construction project cost management and control work.

\subsubsection{Construction link cost control}

The construction link has the greatest impact on the quality of construction project cost management. It is precisely because the construction process will inevitably involve construction personnel, construction equipment, construction materials and other factors, but also need to be coordinated by the finance department, supervision department, equipment management department, etc. The construction work has been completed, resulting in many factors of change. The level of construction project cost management in this section has changed greatly. Therefore, in order to control the cost of construction projects and improve the economic benefits of enterprises, construction enterprises need to strengthen the management and control of construction costs.

During the construction of the construction project, all departments and staff members must carry out engineering visas according to the relevant regulations of China. For example, during the construction process, it is found that the design and the actual construction conditions are inconsistent with the design change, and the engineering quantity and construction materials cost are caused by the design change. If the labor costs and other costs increase, it is necessary to sign the corresponding visa according to the visa system, so as to avoid contradictions in the process of completion settlement and affect the economic benefits of the enterprise. In addition, the project manager shall regularly prepare the engineering quantity report according to the contract regulations and on-site construction progress, and collect the construction money from Party A, so as to ensure the smooth construction of the project.

\subsubsection{Cost control in the completion settlement stage}

After completing the construction of the construction project in accordance with the contractual requirements of both parties, the project A shall pay the construction cost to the construction enterprise. Completion settlement is completed after the project is completed and the two parties have passed the inspection of the construction project. The completion of project settlement is the main basis for verifying the construction project cost management level. Therefore, it is necessary to strengthen the completion settlement review work to improve the construction project cost management level. In order to improve the project cost management and control level in the completion settlement, it is necessary to start from the following aspects:

First, the completion and review of construction engineering projects is complicated. Therefore, it is necessary for the staff to calculate and review the engineering quantities in detail according to the engineering completion drawings, design changes, construction site data, in accordance with relevant standards, so as to avoid the construction enterprises in the completion settlement process. Falsely report the amount of engineering, which in turn affects the construction project cost management and control level. Second, in the audit process, the quota must be accurately selected to check whether the project name, unit of measurement, specifications, etc. are the same as the evaluation form. In addition, the relevant staff members need to analyze in detail whether the 
various fee collection standards are consistent with the cost quota, and it is necessary to check whether the fee collection standard and the cost policy are consistent.

\subsection{Improve the overall quality of cost management personnel}

As the degree of economic globalization continues to increase, talent has become an important factor affecting the development of the country and enterprises. Therefore, in order to promote the stable and sustainable development of construction enterprises, it is necessary to pay attention to the cultivation and introduction of talents. At this stage, some construction engineering cost management personnel in China are not advanced in their work concept and their comprehensive quality is not high enough. In order to effectively solve these problems, relevant departments should pay attention to the cultivation of professional construction engineering cost management talents and improve the overall quality of professional construction engineering cost management talents. And the level of professional competence, improve the overall engineering cost management level of the construction industry, so as to promote the sustainable development of China's construction industry. Construction enterprises need to strengthen the training of engineering cost management personnel, improve their professional knowledge level, improve their legal knowledge level, and also need to strengthen the moral training of engineering cost management personnel, so as to ensure that project cost management personnel can be qualified for project cost management work, which is very important to improve the construction cost management level of the construction industry and promote the stable development of the construction industry. In addition, in order to ensure the smooth progress of the training work, the construction enterprise needs to scientifically develop a training plan to ensure that the entire training work has certain pertinence and effectiveness, so as to enhance the professional ability and comprehensive quality of the project cost management personnel.

\subsection{Scientifically formulate the "price mechanism" project cost management mechanism}

In the past, China has always adopted the project cost management model under the requirements of the planned economic system, but this management model cannot meet the needs of social development. In recent years, China's construction industry has begun to reform, but the management concept of some engineering cost management personnel is still backward, which has adversely affected the construction cost management of construction enterprises. Therefore, in order to improve the construction cost management level of the construction industry, it is necessary to continuously reform and optimize the theoretical system of project cost, change the concept of project cost management personnel, and gradually form a "price mechanism" project cost management mechanism. First of all, in order to promote the continuous development of China's construction industry towards standardization and scientific direction, it is necessary to establish corresponding consulting institutions to provide unified, efficient and scientific services for construction enterprises, so as to promote the stable development of China's construction market. Secondly, construction enterprises need to constantly Adjust the project quota to ensure the separation of volume and price, and use the quota to calculate the actual project quantity; finally, the construction enterprise needs to be scientifically priced according to the market development situation and the actual situation of the project cost management work of the enterprise, thereby improving the construction cost management level of the construction enterprise. 


\subsection{Give full play to the role of government regulation}

In order to improve the project cost management level, it is necessary to give full play to the positive role of the market. However, since the market role is not necessarily positive, in order to avoid the rationality of resource allocation due to market changes, the government departments need to strengthen macroeconomic regulation and control. Therefore, the government departments need to minimize the impact of the administrative department on the market. At the same time, it is necessary to give full play to the responsibilities and functions of the government departments, scientifically formulate the project cost management system, create a good market environment for the construction enterprises, and rationally adjust the relationship between the participants and establish Improve the relevant laws and regulations to regulate the behavior of market entities, so as to improve the construction project cost management level.

\subsection{Strengthen performance appraisal and evaluation of project cost management}

Only by changing the management concept of project cost management personnel and formulating relevant policies cannot guarantee that the project cost management system can be fully implemented. Therefore, in order to ensure that the project cost management system can fully implement and improve the project cost management level, it is necessary to establish and improve the corresponding performance appraisal system and evaluation system. For some departments and individuals with strong sense of responsibility and more serious work, they must give certain rewards, so that the work of project cost management personnel can be stimulated positively; for departments and individuals with weak sense of responsibility and more mistakes in work, they must be given certain Punishment, in case of violations such as dereliction of duty, individuals still need to pursue their legal responsibilities, so as to improve the construction cost management of construction enterprises.

\section{Conclusion}

In short, the quality of construction project cost management will directly affect the construction project management level and affect the economic benefits of the enterprise. Therefore, the construction enterprise needs to dynamically and comprehensively manage and control the project cost during the whole project construction process. Take targeted measures to comprehensively manage project decision-making, bidding, design, etc., and improve the project cost management effect, so as to promote the sustainable development of construction enterprises.

\section{References}

[1] Li Lin. Problems and Countermeasures of Construction Engineering Cost Management [J]. Building Materials Development Guide, 2016, 14(11): 270-271.

[2] Ju Guodong, Wang Yinghua, Zheng Yuwei. Discussion on the Problem of Construction Project Cost Management in the New Era [J]. Global Market, 2016(31):245-245.

[3] Wang Xin. Talking about the Problems Existing in the Implementation of Construction Engineering Cost Management [J]. Sichuan Cement, 2017(12):216.

[4] Chen Yongzhi. Analysis of the Status Quo and Improvement Measures of Construction Engineering Cost Management [J]. Science Technology and Enterprise, 2016(2):41-41.

[5] Zhong Jiawei. Research on Budget Issues in Construction Engineering Cost Management [J]. Engineering Construction, 2017(5): 108-110.

[6] Zhu Huaxu. Problems and Countermeasures of Construction Engineering Cost Management at Present Stage [J]. Studies in Finance and Economics, 2016(S2): 150-154. 